University of Nebraska - Lincoln

DigitalCommons@University of Nebraska - Lincoln

Biological Systems Engineering: Papers and

Publications

Biological Systems Engineering

3-18-2021

\title{
Utilizing digital image processing and two-source energy balance model for the estimation of evapotranspiration of dry edible beans in western Nebraska
}

\author{
Wei-zhen Liang \\ University of Nebraska-Lincoln, wei-zhen.liang@unl.edu \\ Isabella Possignolo \\ University of Nebraska-Lincoln \\ Xin Qiao \\ University of Nebraska-Lincoln, xin.qiao@unl.edu \\ Kendall DeJonge \\ Water Management and Systems Research Unit, USDA-ARS, Kendall.DeJonge@usda.gov \\ Suat Irkmak \\ University of Nebraska-Lincoln, suat.irmak@unl.edu \\ Follow this and additional works at: https://digitalcommons.unl.edu/biosysengfacpub \\ See next page for additional authors \\ Part of the Bioresource and Agricultural Engineering Commons, Environmental Engineering Commons, \\ and the Other Civil and Environmental Engineering Commons
}

Liang, Wei-zhen; Possignolo, Isabella; Qiao, Xin; DeJonge, Kendall; Irkmak, Suat; Heeren, Derek M.; and Rudnick, Daran, "Utilizing digital image processing and two-source energy balance model for the estimation of evapotranspiration of dry edible beans in western Nebraska" (2021). Biological Systems Engineering: Papers and Publications. 748.

https://digitalcommons.unl.edu/biosysengfacpub/748

This Article is brought to you for free and open access by the Biological Systems Engineering at DigitalCommons@University of Nebraska - Lincoln. It has been accepted for inclusion in Biological Systems Engineering: Papers and Publications by an authorized administrator of DigitalCommons@University of Nebraska Lincoln. 
Authors

Wei-zhen Liang, Isabella Possignolo, Xin Qiao, Kendall DeJonge, Suat Irkmak, Derek M. Heeren, and Daran Rudnick 


\title{
Utilizing digital image processing and two-source energy balance model for the estimation of evapotranspiration of dry edible beans in western Nebraska
}

\author{
Wei-zhen Liang ${ }^{1} \cdot$ Isabella Possignolo ${ }^{1,2} \cdot$ Xin Qiao $^{1,2}$ (D) Kendall DeJonge $^{3} \cdot$ Suat Irmak $^{2} \cdot$ Derek Heeren $^{2} \cdot$ \\ Daran Rudnick ${ }^{2}$
}

Received: 16 December 2019 / Accepted: 19 January 2021

(c) The Author(s), under exclusive licence to Springer-Verlag GmbH, DE part of Springer Nature 2021

U.S. government works are not subject to copyright.

\begin{abstract}
Having an accurate yet simple method to estimate crop evapotranspiration $\left(\mathrm{ET}_{\mathrm{C}}\right)$ is a vital component of reliable irrigation scheduling. In this study, two versions of the two-source energy balance (TSEB) model: the TSEB model with the PriestleyTaylor equation (TSEB-PT) and the Penman-Monteith equation (TSEB-PM), were used to estimate ET $_{\mathrm{C}}$ of dry edible beans in western Nebraska. Compared with previous studies, this study is unique in that a Visual Basic software-Crop Canopy Image Analyzer (CCIA) was developed to process digitally captured RGB canopy images to obtain necessary canopy cover (CC) parameters for the TSEB models such as CC percentage and leaf shape factor (leaf area divided by its perimeter). Software-estimated CC percentage was closely correlated with commercial sensor-derived CC percentage with an $R^{2}$ of 0.96. Additionally, estimated leaf shape factor was closely correlated with measured leaf shape factor with $R^{2}$ of 0.99 . Both TSEB-PT and TSEB-PM models estimated $\mathrm{ET}_{\mathrm{C}}$ well for fully irrigated dry edible beans with a root-mean-square error (RMSE) that ranged from 0.95 to $1.63 \mathrm{~mm} \mathrm{day}^{-1}$ in 2018 , and 0.75 to $1.35 \mathrm{~mm} \mathrm{day}^{-1}$ in 2019 , as compared to $\mathrm{ET}_{\mathrm{C}}$ estimated from FAO56. Furthermore, $\mathrm{ET}_{\mathrm{C}}$ from TSEB-PT and TSEB-PM were compared with a soil water balance-derived ET $_{\mathrm{C}}$ and the RMSE ranged from 2.03 to $9.65 \mathrm{~mm}$ in an approximate 1-week period under four irrigation treatments ranging from dry land to fully irrigated. The proposed methods in this study, by integrating digital image processing with TSEB models, have great potential to be automated and used in field-scale operations for various irrigation management scenarios of many crops.
\end{abstract}

\section{Introduction}

Water scarcity is one of the main factors constraining agricultural production in arid and semi-arid areas. The knowledge of crop evapotranspiration $\left(\mathrm{ET}_{\mathrm{C}}\right)$, as well as the mechanism of $\mathrm{ET}_{\mathrm{C}}$ partitioning into surface evaporation (E) and crop transpiration $(\mathrm{T})$, is very important for precise quantification of the water balance in irrigation scheduling and

Xin Qiao

xin.qiao@unl.edu

1 Panhandle Research and Extension Center, University of Nebraska-Lincoln, 4502 Avenue I, Scottsbluff, NE, USA

2 Department of Biological Systems Engineering, University of Nebraska-Lincoln, 200 L.W. Chase Hall, Lincoln, NE, USA

3 Water Management and Systems Research Unit, USDA-ARS, 2150 Centre Ave, Bldg. D Ste. 320, Fort Collins, CO, USA management, optimizing crop production, identifying crop stress, and drought impacts (Yang et al. 2018).

Nebraska is the predominant irrigated agriculture state in the United States, with 3.3 million ha of irrigated lands which accounts for $14.9 \%$ of total irrigated lands in the U.S. (USDA 2013). In western Nebraska, where rainfall is much less than the eastern part of the state, irrigation is critical, since $\mathrm{ET}_{\mathrm{C}}$ for regional crops always exceeds inseason precipitation (Yonts et al. 2018). Particularly for dry edible bean (Phaseolus vulgaris L.) production in western Nebraska, $90 \%$ of its production is on irrigated lands (Yonts et al. 2018). Depending on the source of water, irrigated lands in western Nebraska are subject to unstable and variable surface water supply or groundwater allocation of 178 hectare-cm per certified irrigated hectare per consecutive 5 years (North Platte Natural Resources District 2019). The cutoff of surface water supply to eastern Wyoming and western Nebraska in 2019 due to a tunnel collapse (University of Nebraska and University of Wyoming Extension 2019) further emphasizes the importance of understanding and 
quantifying crop consumptive use (loss of water through ET) when water supply is limited.

There are many methods available to quantify $\mathrm{ET}_{\mathrm{C}}$. One simple method to determine crop ET is by solving the soil water balance equation for week-long or 10-day periods (Allen et al. 1998):

$E T_{c}=I+P-R O-D P+C R \pm \Delta S F \pm \Delta S W$,

where during a time period, $I$ is net irrigation applied in $\mathrm{mm}$; $P$ is precipitation in $\mathrm{mm} ; R O$ is runoff in $\mathrm{mm} ; D P$ is deep percolation in $\mathrm{mm} ; C R$ is possible water transported upward by capillary rise from a shallow water table or water transported horizontally by subsurface flow $(\Delta S F)$ in $\mathrm{mm} ; \Delta S W$ is change in soil water storage in $\mathrm{mm}$. Since $P$ and $I$ can be straightforwardly obtained and recorded, and runoff or deep percolation can be minimized by management, determination of $\Delta \mathrm{SW}$ is most critical when using soil water balance to calculate ET. Water transported by capillary rise $(C R)$ or subsurface flow $(\triangle S F)$ can be assumed to be zero for shorttime periods. Soil water content can be measured by taking soil gravimetric samples, or using variety of soil moisture sensors such as neutron probe and electromagnetic sensors (Evett et al. 2006; Singh et al. 2018). However, measuring soil water content below the root zone can be quite challenging depending on the crop root depth and is critically important for accuracy of $E T_{C}$ estimation using soil water balance method (Evett et al. 2012). If soil water content below a root zone is measured and remains relatively constant, it verifies that no deep percolation has occurred, and thus, $E T$ estimation is accurate. To the contrary, deep percolation will have to be estimated if soil water content below root zone constantly fluctuates.

The FAO Irrigation and Drainage Paper No. 56 (Allen et al. 1998 ) is widely adopted worldwide to estimate $E T_{C}$ using the concept of reference evapotranspiration $\left(E T_{o}\right)$ and cropspecific coefficient $\left(K_{C}\right)$. Application of the FAO56 method requires accurate and representative weather data, specifically on-site temperature, humidity, solar radiation, and wind speed (Pereira et al. 2015). However, such information is not always available for individual fields, and incomplete, inaccurate, or interpolation of proximate weather data to calculate $E T_{C}$ can lead to erroneous results (Benli et al. 2010; Kwon and Choi 2011). FAO56 provides method to estimates $\mathrm{ET}_{\mathrm{C}}$ of plants that are under standard or well-managed conditions. For plants that are under non-standard conditions such as suffering from low soil fertility, salt toxicity, waterlogging, pest, or disease pressure, $\mathrm{K}_{\mathrm{C}}$ will have to be corrected and adjusted accordingly (Allen et al. 1998). In reality, crops grown on a large or small production fields are often affected by various soil types, elevations, and slopes, which combination of these conditions can be favorable/unfavorable for yield production (Kravchenko and Bullock 2000; Di Virgilio et al. 2007). Therefore, application of the FAO56 method under such conditions will have to be adjusted according to actual conditions. Since $E T_{o}$ remains the same, $K_{C}$ can be adjusted and scaled by remotely sensed vegetation indexes (Neale et al. 1990; Kamble et al. 2013).

Other approaches to quantify $\mathrm{ET}_{\mathrm{C}}$ at large spatial scales include measuring canopy cover $(\mathrm{CC})$ temperature and using an energy balance model such as Surface Energy Balance Algorithm for Land (SEBAL), Mapping Evapotranspiration at High Resolution and with Internalized Calibration (METRIC), and two-source energy balance model (TSEB). The two models SEBAL and METRIC have been used extensively to quantify $\mathrm{ET}_{\mathrm{C}}$, using satellite-based land surface temperatures (LST) (Singh et al. 2008; Allen et al. 2011; Papadavid et al. 2013). However, most satellite-based LST images are not simultaneously available in high-spatial $(\sim 30 \mathrm{~m})$ or temporal resolution (daily or smaller time steps). To address this issue, the backward-averaged iterative two-source surface temperature and energy balance solution (BAITSS) model was developed to calculate ET by combining continuous gridded weather data and remote-sensing-based vegetation indexes (Dhungel et al. 2016). In contrast to widely used instantaneous surface energy balance models, BAITSSS solves surface energy balance (including surface temperature) and water balance components for each time step (hourly or smaller) in a time-series without using thermal-based or measured surface temperature. It utilizes flux gradient equations to estimate latent and sensible heat flux and tracks soil moisture at the root zone to apply irrigation. Jarvis-type algorithm is utilized to calculate dynamic canopy resistance with weighting functions representing plant response to solar radiation, air temperature, vapor pressure deficit, and soil moisture.

The TSEB model has been proposed to estimate $E T_{C}$, where sensible and latent heat fluxes for both soil $\left(T_{S}\right)$ and canopy $\left(T_{C}\right)$ temperatures can be calculated separately using a single measurement of composite surface (soil and canopy) temperature $\left(T_{R}\right)$, meteorological variables (air temperature, wind speed, solar radiation, and relative humidity), and vegetation information (crop height, CC percentage, and leaf area index) (Norman et al. 1995). $T_{R}$ is assumed that the sum of $T_{c}$ and $T_{s}$ weighted by CC (Norman et al. 1995):

$T_{R}^{4}=f_{S} T_{c}^{4}+\left(1-f_{S}\right) T_{s}^{4}$,

where $f_{S}$ is the fraction of CC appearing in the field of view of an Infrared Radiometric Thermometer (IRT). The fraction of the field of view of IRT can be related to view the zenith angle $(\theta)$ and leaf area index (LAI) (Eq. 3):

$f_{S}=1-\exp \left(\frac{-0.5 \mathrm{LAI}}{\cos \theta}\right)$.

Previous TSEB studies have used commercial plant canopy analyzers such as the LAI-2000 (LI-COR Biosciences, Lincoln, NE, U.S.) to obtain LAI (Norman et al. 
1995; Colaizzi et al. 2010, 2012; Hoffman et al. 2016; Yang et al. 2018). However, such instruments are mostly used by research facilities and are not feasible for commercial farm use due to cost and interpretability of data. In addition, several important parameters in TSEB model are hard to acquire, such as aerodynamic resistance, canopy resistance at the boundary layer, and soil resistance (Norman et al. 1995; Kustas and Norman 1999). The boundary layer of canopy resistance can be estimated by LAI, wind speed, canopy height, and leaf area (A) divided by leaf perimeter (P) (A/P) (Norman et al. 1995). The soil resistance is estimated by canopy height, LAI, wind speed above soil surface, and A/P (Kustas and Norman 1999). The soil resistance can also be calculated using soil moisture at the soil surface (Dhungel et al. 2018). Other than TSEB model, LAI is an important input parameter to calculate either canopy resistance at boundary layer or soil resistance for many energy balance models (Singh et al. 2008; Allen et al. 2011; Papadavid et al. 2013; Dhungel et al. 2018). In this study, instead of measuring LAI to estimate $\mathrm{f}_{\mathrm{S}}$, we proposed a new method using RGB CC picture taken from field and a software modified from a soybean CC software (Liang et al. 2018). A previous study using digital photographs was shown to reduce errors of $f_{S}$ calculations by $15 \%$ compared with the commonly used clumping index approach such as aircraft and Landsat imagery (Colaizzi et al. 2012). However, to our best knowledge, there have been no studies that use digital images to estimate leaf shape factor and subsequently use in the calculation of TSEB models.

Hence, the objectives of this paper were to: (1) develop a software/algorithm to estimate dry edible bean canopy cover percentage and leaf shape factor; (2) evaluate performance of the software on determination of canopy parameters; (3) calculate daily $\mathrm{ET}_{\mathrm{C}}$ using TSEB models using software determined canopy parameters; (4) compare daily $E T_{C}$ computed from TSEB models with FAO56 computed $\mathrm{ET}_{\mathrm{C}}$ and soil water balance determined $E T_{C}$ using neutron probe readings.

\section{Materials and methods}

\section{Experimental site and data collection}

The experiment was conducted at the University of Nebraska-Lincoln, Panhandle Research and Extension Center (PHREC) in Scottsbluff, NE (41 ${ }^{\circ} 53^{\prime} 34.93^{\prime \prime} \mathrm{N}$, $103^{\circ} 41^{\prime} 2.04^{\prime \prime} \mathrm{W}$, elevation $1189 \mathrm{~m}$ ) in 2018 and 2019. The climate in the region is semi-arid with annual average rainfall of $398 \mathrm{~mm}$. Soil in the experimental field is Tripp very fine sandy loam, with up to $3 \%$ slopes. Great Northern Beans were planted at $55 \mathrm{~cm}$ row spacing on June 7 th and June 10th in 2018 and 2019, respectively. Beans were harvested with a commercial combine (John Deere 9500, John Deere, Moline, Illinois, U.S.) equipped with Global Positioning System (GPS) enabled yield monitor (Ag Leader Insight yield monitor, Ag Leader Technology, Inc., Ames, Iowa, U.S.). Beans were harvested on October 19th in 2018 and October 4th in 2019. The experiment was a randomized complete design (RCD) with 4 irrigation treatments $(0,33$, 66 , and $100 \%$ of full irrigation) and 3 replicates. The full irrigation treatment (FIT) was meant to fully satisfy crop water needs which were to replenish crop evapotranspiration $\left(E T_{C}\right)$. Crop evapotranspiration was calculated using the single-crop coefficient method presented in FAO56 (Allen et al. 1998) with reference ET ( $\left.E T_{o}\right)$ calculated using the Penman-Monteith equation:

$E T_{o}=\frac{0.408 \Delta\left(R_{n}-G\right)+\gamma \frac{900}{T+273} u_{2}\left(e_{s}-e_{a}\right)}{\Delta+\gamma\left(1+0.34 u_{2}\right)}$,

where $E T_{o}$ is reference evapotranspiration in $\mathrm{mm} \mathrm{day}^{-1}, R_{n}$ is net radiation at the crop surface in $\mathrm{MJ} \mathrm{m}^{-2} \mathrm{day}^{-1}, \mathrm{G}$ is soil heat flux density in $\mathrm{MJ} \mathrm{m}^{-2} \mathrm{day}^{-1}$, $\mathrm{T}$ is mean daily air temperature at $2 \mathrm{~m}$ height in ${ }^{\circ} \mathrm{C}, u_{2}$ is wind speed at $2 \mathrm{~m}$ height in $\mathrm{m} \mathrm{s}^{-1}, e_{s}$ is saturation vapor pressure in $\mathrm{kPa}, e_{a}$ is actual vapor pressure in $\mathrm{kPa}, e_{s}-e_{a}$ is saturation vapor pressure deficit in $\mathrm{kPa}, \Delta$ is slope vapor pressure curve in $\mathrm{kPa}^{\circ} \mathrm{C}^{-1}$, and $\gamma$ is psychrometric constant in $\mathrm{kPa}^{\circ} \mathrm{C}^{-1}$. Dry edible bean crop coefficients were adopted from growth stage charts provided by University of Nebraska Extension (2020). Single crop coefficients of dry beans are shown in Fig. 1.

Irrigation was applied using a Zimmatic (Lindsay Corporation, Omaha, Nebraska, U.S.) variable rate linear move sprinkler irrigation system. Irrigation was applied to all treatments when management allowed depletion (MAD) of FIT was at $40 \%$, and irrigation rates of treatments were calculated based on percentage of FIT. An on-site weather

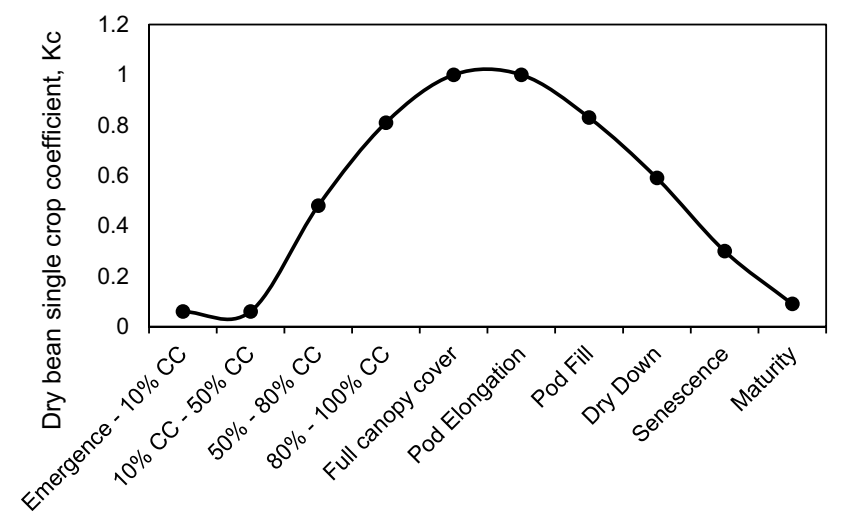

Fig. 1 Single crop coefficients $\left(K_{c}\right)$ for dry beans when weekly reference evapotranspiration $\left(E T_{o}\right)$ is $25.4 \mathrm{~mm}$. For $K_{c}$ at weekly $E T_{o}$ that are greater than $25.4 \mathrm{~mm}$, readers, please refer to https://cropwatch. unl.edu/et_resources 
station ( $1.2 \mathrm{~km}$ from experimental field) that is part of the Automated Weather Data Network operated by the High Plains Regional Climate Center was used to collect hourly air temperature, relative humidity, solar radiation, wind speed, and precipitation. Plots were $10 \mathrm{~m}$ wide by $15 \mathrm{~m}$ long. Each plot consisted of 18 crop rows and the middle 6 rows were used for sensor installation, image acquisition, and data collection. Composite temperature of crop canopy and soil was measured using infrared thermometers (IRTs) from Apogee Instruments (Apogee Instruments, Inc., Logan, Utah, U.S.). The model SI-431, which has a field of view of $14^{\circ}$ half angle and accuracy of $\pm 0.3{ }^{\circ} \mathrm{C}$ with SDI12 output were used in this study. The IRTs were installed at all three replications of each irrigation treatment. The IRTs were mounted to a metal pole $1.2 \mathrm{~m}$ above the ground and were angled $45^{\circ}$ below horizon and parallel with the crop row. Heights of IRTs were kept the same throughout the season. According to the height and view angle of the IRTs, the total area seen by the sensor was approximately $0.61 \mathrm{~m}^{2}$ at maximum. Data from the IRTs were continuously recorded every 5 min using CR300 data loggers (Campbell Scientific Inc., Logan, Utah, U.S.). In addition to IRTs, at each plot, a neutron probe access tube was installed at $1.2-\mathrm{m}$ depth and a 503 DR Hydroprobe (CPN International, Inc., Concord, Carlifornia, U.S.) was used to measure soil water content at $0.3 \mathrm{~m}$ increment at weekly basis during the growing seasons. Soil water content data were therefore used to compute $\mathrm{ET}_{\mathrm{C}}$ using Eq. 1.

\section{The image processing software-Crop Canopy Image Analyzer (CCIA)}

\section{Determination of canopy cover percentage}

Canopy cover images of dry beans were taken on three dates in 2018 (July 6th, July 27th, and August 9th and four dates in 2019 (July 18th, July 22nd, August 1st, and August 14th). Images were taken at canopies that were within the viewing footprint of IRT at each irrigation treatment plot. An RGB camera $(1500 \times 1125$ pixels) on a tablet (Samsung Galaxy Tablet 10, Samsung Group, Seoul, South Korea) was used to take images at approximately $30 \mathrm{~cm}$ height above the canopy at 45 downward degrees. Twenty representative canopy images from various treatment plots during different growth stages were randomly selected during 2018 to classify color groups and train the in-house designed software CCIA for estimating CC percentage. Since LAI is an important parameter in TSEB models for calculating CC percentage (Eq. 3); therefore, during 2019, in addition to CC images, leaf area index (LAI) was taken at the same time and same locations using LAI-2000 (LI-COR Inc., Lincoln, U.S.). Then, LAIderived CC was compared to CCIA-estimated CC to validate the accuracy of the software algorithm. To estimate leaf area
(A) and leaf perimeter $(\mathrm{P})$ for calculating soil resistance in TSEB models, three dry bean leaves were randomly taken from each irrigation treatment on July 18th, July 25th, and August 2nd of 2019. CCIA utilizes Mahalanobis distance and Canny edge detection method to estimate canopy cover and leaf shape factor, respectively.

Mahalanobis distance (Devroye et al. 1996) is a classification method for analyzing leaf color, and it has been used to determine soybean A (Liang et al. 2018). The Mahalanobis distance (Md) (Eq. 5) measures the similarity between an unknown sample group and a known sample group:

$M d=\sqrt{(X-Y)^{T} S^{-1}(X-Y)}$,

where $X$ is a three-dimensional vector $(R, G, B)$, which represented pixels from the image to be processed. $Y$ is a threedimensional vector $(R, G, B)$, which represents the average of reference pixels (reference group) for each class to be identified. The Mahalanobis color distance standardizes the influence of the distribution of each feature considering the correlation between each pair of terms. In the case of RGB color images, $S$ is computed as (Eq. 6):

$S=\left[\begin{array}{lll}\sigma_{R_{\text {ref }} R_{\text {ref }}} & \sigma_{R_{\text {ref }} G_{\text {ref }}} & \sigma_{R_{\text {ref }} B_{\text {ref }}} \\ \sigma_{G_{\text {ref }} R_{\text {ref }}} & \sigma_{\text {ref }_{\text {ref }} G_{\text {ref }}} & \sigma_{G_{\text {ref }} B_{\text {ref }}} \\ \sigma_{B_{\text {ref }} R_{\text {ref }}} & \sigma_{B_{\text {ref }} G_{\text {ref }}} & \sigma_{\text {ref }} B_{\text {ref }}\end{array}\right]$,

and as an example, the elements of $S$ are calculated as:

$\sigma_{G_{\mathrm{ref}} R_{\mathrm{ref}}}=\sigma_{R_{\mathrm{ref}} G_{\mathrm{ref}}}=\frac{\sum_{i=1}^{n}\left(R_{i}-\bar{R}\right)\left(G_{i}-\bar{G}\right)}{n-1}$,

where $\sigma$ is covariance of $R, G, B$ reference group colors, $R_{i}$, $\underline{G}_{i}, \underline{B}_{i}$ are the values of the $i$ th match $(i=1,2,3, \ldots n)$, and $R, G, B$ are the mean color values for $R, G, B$ in the given image, respectively.

In the proposed methodology of this work, six reference groups of pixels were selected to generate the classification, in which every group represented relevant characteristics of dry bean leaves and background classes. The six groups identified were: leaves (light green leaves, light yellow leaves, and dark green leaves) and background (shadow, soil, and silver metal rods which data loggers were mounted to). If any of these classes were not present, or a new class appeared on the image, the number and/or the group labels were modified in the program.

Each reference group was manually selected from a set of 20 canopy images taken in 2018 growing season and a set of 20-30 colors in each reference group was chosen. The 20 canopy images were used to train CCIA to determine the group that each pixel belongs to. After training CCIA, Md was computed over a set of 160 images in our software, and each pixel was assigned to the class with the lowest distance 
to calibrate and test the accuracy in the determination of A. To implement the classification and provide a graphical interface to the user, the software was developed using Visual Basic 2017. Details of the identified leaves were shown as green color and background was shown as pink color in the output figures. CC percentage $\left(f_{s}\right)$ was calculated using green area pixel number $\left(N_{G}\right)$ and background pixel number $\left(N_{B}\right)$ (Eq. 8):

$f_{s}=\frac{N_{G}}{N_{G}+N_{B}} \times 100 \%$.

To evaluate the performance of CCIA on estimating $f_{S}$, the $\mathrm{CC}$ from the software and from corresponding LAI measurements $\left(\mathrm{f}_{\mathrm{LAI}}\right)$ taken on July 18th, July 30th, and August 5th, 2019 at each irrigation treatments with three replicates were selected and compared.

\section{Determination of leaf shape factor}

As mentioned earlier, the boundary layer of canopy resistance and soil resistance are estimated from leaf shape factor $(L s)$, which is calculated by $A$ divided $P$ (Norman et al. 1995; Kustas and Norman 1999). Manual Ls measurements can be very complex and time-consuming. Therefore, digitally determined $L_{s}$ using would be much more efficient. In our software, algorithm determined $L_{S}$ is defined as the leaf area $\left(N_{G}\right)$ in pixel number divided by $\mathrm{P}$ in pixel number multiplied by a coefficient $(\mathrm{cm})$ :

$L_{s}=\frac{N_{G}}{P} \times \lambda$.

Coefficient is slope of regression line by fitting measured leaf shape factor ( $L_{\text {meas }}$ ) to $L_{S}$, where $L_{A}$ is calculated as:

$L_{\text {meas }}=\frac{A_{\text {meas }}}{P_{\text {meas }}}$,

where $A_{\text {meas }}$ is measured leaf area in $\mathrm{cm}^{2}$ and $P_{\text {meas }}$ is measured leaf perimeter in $\mathrm{cm}$. To obtain $A_{\text {meas }}$, a dime coin was placed with a leaf as a reference when taking the image (Fig. 6d and e). It was assumed that the leaf area is proportional to leaf pixel numbers and dime area is proportional to dime pixel number. Since the area of a dime is known $\left(2.5193 \mathrm{~cm}^{2}\right)$, by counting the pixel number of the dime and leaf, $A_{\text {meas }}$ can be calculated through Eq. 11:

$A_{\text {meas }}=\frac{A_{\text {coin }} \times N_{\text {leaf }}}{N_{\text {coin }}}$,

where $N_{\text {coin }}$ is number of pixels in the coin and $N_{\text {leaf }}$ is number of pixels in the leaf, $A_{\text {coin }}=$ coin area (U.S. dime, $2.5193 \mathrm{~cm}^{2}$ ); The measured leaf perimeter $P_{\text {meas }}$ was measured manually with cotton string and ruler in centimeter. The pixel number of leaf area was obtained using Md method as described previously. Canny edge detection method was used for calculating leaf perimeter pixel number (Canny 1986), and it has been used to determine soybean leaf edge successfully (Liang et al. 2018). Canny edge detection method outlines edges of object by looking for the local maximum of the gradient of input image. It calculated the gradient using the derivative of the Gaussian filter (Eq. 12) to remove noise (non-leaf perimeter structures in this case) in an image. The Sobel operators were applied to find the gradient (Eqs. 13, 14, and 15) and direction (Eq. 16) (Sobel 1978):

Gaussian_filter $=\frac{1}{159}\left[\begin{array}{ccccc}2 & 4 & 5 & 4 & 2 \\ 4 & 9 & 12 & 9 & 4 \\ 5 & 12 & 15 & 12 & 5 \\ 4 & 9 & 12 & 9 & 4 \\ 2 & 4 & 5 & 4 & 2\end{array}\right]$

$$
\begin{aligned}
G_{x}= & \{(-1) f(x-1, y-1)+f(x+1, y-1)-2 f(x-1, y) \\
& +2 f(x+1, y)+(-1) f(x-1, y+1)+f(x+1, y+1)\}
\end{aligned}
$$

$G_{y}=\{(-1) f(x-1, y-1)+(-2) f(x, y-1)+(-1) f(x+1, y-1)$

$+f(x-1, y+1)+2 f(x, y+1)+f(x+1, y+1)\}$

$|G|=\sqrt{\left(G_{x}\right)^{2}+\left(G_{y}\right)^{2}}$

$\theta=\tan ^{-1} \frac{G_{y}}{G_{x}}$.

The Canny detection method uses two thresholds to detect strong and weak edges. It includes the weak edges in the output only if they are connected to strong edges. Nonmaximum suppression used to get rid of spurious response to detect edges for shape and two threshold values $\left(t_{1}, t_{2}\right)$ were applied to determine the potential edges of leaf image $\left(t_{1}<t_{2}\right)$. The recommended $t_{2}$ to $t_{1}$ is 3:1 (Canny 1986), and the threshold of $t_{2}$ and $t_{1}$ was set 20 and 7 , respectively, in our study (Liang et al. 2018). The leaf area was determined first, transformed the whole leaf as green color (leaf vein included), and then used the Canny detection method to find the perimeter of the leaf.

Two-way ANOVA was used to evaluate whether $L_{S}$ change significantly with sampling dates and irrigation treatments using SAS (SAS, 2013, Institute SAS Inc., Cary, NC). Such statistical test is necessary, because images were not acquired every day for the entire growing seasons, yet later calculations in TSEB models require hourly $L_{S}$ input. In the case of insignificant differences $(p>0.05)$, it will be concluded that average $L_{S}$ can be used during the full growing season. If significant differences are present for $L_{S}$ with sampling dates and treatments, average $L_{S}$ cannot be 
used for values that are between sampling dates and must be interpolated.

\section{TSEB-Priestley-Taylor (PT) model}

The TSEB model was originally developed by Norman et al. (1995) to make use of remotely sensed radiometric surface temperatures to estimate soil evaporation and canopy transpiration. The model was further modified by Kustas and Norman (1999) by improving the soil surface resistance formulation and net radiation partitioning between soil and canopy components. The net radiation is partitioned between the vegetated canopy and soil, and can be expressed as:

$R_{n}=R_{n s}+R_{n c}=H+L E+G$

where $R_{n}$ is net radiation $\left(\mathrm{W} \mathrm{m}^{-2}\right)$, and $R_{n s}$ and $R_{n c}$ are the net radiation for soil and vegetation canopy $\left(\mathrm{W} \mathrm{m}^{-2}\right)$, respectively; $\mathrm{H}$ and $\mathrm{LE}$ are sensible and latent heat fluxes $\left(\mathrm{W} \mathrm{m}^{-2}\right)$, respectively, and $\mathrm{G}$ is the soil heat flux $\left(\mathrm{W} \mathrm{m}^{-2}\right)$. The energy balance for the soil and vegetated canopy can be expressed as (Kustas and Norman 1999):

$R_{n s}=H_{s}+L E_{s}+G$

$R_{n c}=H_{c}+L E_{c}$,

where $H_{s}$ and $H_{c}$ are the sensible heat fluxes for the soil and canopy $\left(\mathrm{W} \mathrm{m}^{-2}\right)$, respectively, and $L E_{s}$ and $L E_{c}$ are the latent heat fluxes for the soil and canopy $\left(\mathrm{W} \mathrm{m}^{-2}\right)$, respectively. $G$ is parameterized with the phase difference approach:

$G=R_{n s}\left\{a \cdot \cos \left[\frac{2 \pi}{b}(t+c)\right]\right\}$,

where $t$ is the solar time angle (s), a is the amplitude parameter (dimensionless), and $\mathrm{c}$ is the shift (s). In this study, parameters $\mathrm{a}, \mathrm{b}$, and $\mathrm{c}$ take the values of $0.3,86,400$, and 10,800 following Colaizzi et al. (2012).

In this study, $H$ is calculated by temperature gradienttransport resistance networks between soil, canopy, and air above the canopy. The flux of heat from the soil surface to atmosphere is in parallel with the flux of heat from the canopy to atmosphere (Norman et al. 1995), describing a parallel resistance framework and assuming no interactions between soil and canopy (Norman et al. 1995). The parallel network is prone to errors when vegetation cover varies, but such errors can be moderated by accounting for within-canopy air temperature $\left(T_{a c}\right)$, and change the parallel network to series resistance network (Kustas and Norman 1999; Li et al. 2005). In this study, since there could be differences in canopy cover percentage due to implementation of irrigation treatments, the series resistance network was applied, in which $\mathrm{H}_{\mathrm{c}}, \mathrm{H}_{\mathrm{s}}$, and the sum of both terms are calculated as (Norman et al. 1995; Kustas and Norman 1999; Li et al. 2005):

$H_{c}=\rho C_{p} \frac{T_{c}-T_{a c}}{r_{x}}$

$H_{s}=\rho C_{p} \frac{T_{s}-T_{a c}}{r_{s}}$

$H=\rho C_{p} \frac{T_{a c}-T_{a}}{r_{a}}$,

where $\rho$ is the air density $\left(\mathrm{kg} \mathrm{m}^{-3}\right), C_{p}$ is the specific heat of air $\left(\mathrm{J} \mathrm{kg}^{-1} \mathrm{~K}^{-1}\right), \mathrm{T}_{\mathrm{s}}$ is the soil temperature $(K), T_{c}$ is the canopy temperature $(K), T_{a c}$ and $T_{a}$ are the air temperature within the canopy boundary layer and air temperature $(K)$, respectively, $r_{a}$ is the aerodynamic resistance $\left(\mathrm{s} \mathrm{m}^{-1}\right), r_{x}$ is the resistance in the boundary layer near the canopy $\left(\mathrm{s} \mathrm{m}^{-1}\right)$, and $r_{s}$ is the resistance to heat flux in the boundary layer above the soil surface $\left(\mathrm{s} \mathrm{m}^{-1}\right)$. The $r_{a}, r_{x}$, and $r_{s}$ are calculated according to Norman et al. (1995) and Kustas and Norman (1999). The leaf shape factor was calculated for $r_{s}$ and $r_{x}$. The $r_{s}$ is calculated as:

$r_{s}=\frac{1}{c\left(T_{s}-T_{c}\right)^{1 / 3}+b u_{s}}$,

where $c=0.0025, b=0.012$, and $u_{s}$ is wind speed at the height of soil surface, $\mathrm{m} \mathrm{s}^{-1}$ (Kustas and Norman 1999).

The $u_{s}$ is calculated as:

$u_{s}=u_{c} \exp \left(-a\left(1-\frac{0.05}{h_{c}}\right)\right)$,

where $u_{c}$ is the wind speed at top canopy $\left(\mathrm{m} \mathrm{s}^{-1}\right), \mathrm{h}_{\mathrm{c}}$ is canopy height $(m)$, and factor $a$ is calculated as (Norman et al. 1995):

$a=0.28 F^{2 / 3} h_{c}^{1 / 3} s^{-1 / 3}$,

where $s$ is mean leaf size given by four times the leaf area divided by the leaf perimeter (Norman et al. 1995). In this article, leaf area divided by leaf perimeter is defined as leaf shape factor $\left(L_{S}\right)$ (Eq. 9). Hence, $s$ is $4 \times L s$.

The $r_{x}$ is calculated as:

$r_{x}=\frac{C^{\prime}}{F}\left(\frac{s}{U_{d+Z_{m}}}\right)^{1 / 2}$,

where $C^{\prime}$ is derived from weighting a coefficient for leaf boundary layer resistance over the height of the canopy (Norman et al. 1995) and equation for calculating $U_{d+Z_{m}}$ can be found in Norman et al. (1995). 
The TSEB-PT model uses a modified Priestley-Taylor formulation to parameterize the canopy transpiration:

$L E_{c}=\alpha_{P T} f_{S} \frac{\Delta}{\Delta+\gamma} R_{n c}$,

where $\alpha_{\mathrm{PT}}$ is the Priestley-Taylor parameter (dimensionless), $\Delta$ is the slope of the saturation vapor pressure versus temperature curve $\left(\mathrm{kPa}^{\circ} \mathrm{C}^{-1}\right)$, and $\gamma$ is the psychrometric constant $\left(\mathrm{kPa}^{\circ} \mathrm{C}^{-1}\right)$. An initial estimate of $\mathrm{T}_{\mathrm{C}}$ can be derived as follows:

$T_{c}=T_{a}+\frac{R_{n c} r_{a}}{\rho C_{p}}\left[1.0-\alpha_{P T} f_{S} \frac{\Delta}{\Delta+\gamma}\right]$.

Accordingly, $T_{S}$ is calculated with an in the initial estimate of $T_{S}$, and then $r_{s}$ can be estimated with the temperature gradient between the soil and canopy described in Kustas and Norman (1999). From Eq. 21 to Eq. 23, the component $H_{S}$ can be calculated and the $L E_{C}$ and the $L E_{S}$ are solved as residual terms. To obtain a realistic estimation of surface heat fluxes under water-stressed conditions, the $\alpha_{\mathrm{PT}}$ is iteratively decreased until $\mathrm{LE}_{\mathrm{S}}$ exceeds zero and the initial $\alpha_{\mathrm{PT}}$ is set 1.26 (Kustas and Norman 1999). The detailed description of the TSEB model and the parameterization of the resistance network can be found in Norman et al. (1995) and Kustas and Norman (1999).

\section{TSEB-Penman-Monteith (PM) model}

The TSEB model was revised by Colaizzi et al. (2012) using the Penman-Monteith equation instead of the Priestley-Taylor formulation to account for the impact of advection over semi-arid environment. This revised version of the TSEB model is termed as TSEB-PM. The effects of varying vapor pressure deficit can thus be taken into account in the TSEB-PM model. The canopy transpiration is characterized using the Penman-Monteith equation:

$L E_{c}=f_{S}\left(\frac{\Delta R_{n c}}{\Delta+\gamma^{*}}+\frac{\rho C_{p}\left(e_{s}-e_{a}\right)}{r_{a}\left(\Delta+\gamma^{*}\right)}\right)$,

and $T_{c}$ is initialized as:

$T_{c}=T_{a}+\frac{R_{n c} r_{a} \gamma^{*}}{\rho C_{p}\left(\Delta+\gamma^{*}\right)}-\frac{e_{s}-e_{a}}{\Delta+\gamma^{*}}$,

where $\gamma^{*}=\gamma\left(1+r_{c} / r_{a}\right), \mathrm{r}_{\mathrm{c}}$ is the bulk canopy resistance (s $\left.\mathrm{m}^{-1}\right), r_{a}$ is the aerodynamic resistance between the canopy and the air above the canopy $\left(\mathrm{s} \mathrm{m}^{-1}\right)$, and $e_{a}$ and $e_{s}$ are the actual and saturation vapor pressure of the air $(\mathrm{kPa})$, respectively. Similar to TSEB-PT, the TSEB-PM model was iteratively implemented. During the iterative procedure, $r_{c}$ increases from $10 \mathrm{~s} \mathrm{~m}^{-1}$ with an increment of $20 \mathrm{~s} \mathrm{~m}^{-1}$ and terminates at $1000 \mathrm{~s} \mathrm{~m}^{-1}$, or until $\mathrm{LE}_{\mathrm{S}}$ exceeds zero. Comprehensive details of the TSEB-PM can be found in Colaizzi et al. (2012).

\section{Software and TSEB model evaluation}

To determine the performance of the software on determination of $f_{S}$ and $L_{S}$, root-mean-square error (RMSE) values for pairs of software-estimated $f_{S}$ and measured $f_{M}\left(f_{\mathrm{LAI}}\right)$, and software-estimated $L_{S}$ and measured $L_{M}$ were calculated using:

$\mathrm{RMSE}=\sqrt{\frac{\sum_{i=1}^{n}(E-M)_{i}^{2}}{n}}$,

where $n$ is number of measurements; and $E$ and $M$ are estimated values (from software) and measured values, respectively. Leaf area shape factor and CC were linear interpolated hourly between sampling intervals. Crop evapotranspiration for each irrigation treatment was calculated using TSEB-PT and TSEB-PM models on hourly basis, and then accumulated to daily (24 h, from 0:00 to 23:00) $\mathrm{ET}_{\mathrm{C}}$ results. Daily $\mathrm{ET}_{\mathrm{C}}$ calculated by FAO56 were used as reference and compared with TSEB-PT and TSEB-PM values for $100 \%$ irrigation treatments during 2018 and 2019. Soil water balancederived $\mathrm{ET}_{\mathrm{C}}$ values between neutron probe sampling dates were also used to compare against daily TSEB-ET ${ }_{C}$ values during 2019 study. The RMSE between estimated $\mathrm{ET}_{\mathrm{C}}$ values (by TSEB) and estimated ET values (by FAO56 or neutron probe) were also calculated using Eq. 32.

\section{Results and discussion}

\section{Weather, irrigation treatments, and yield}

Amount of irrigation for each treatment during each growing season is listed in Table 1. In 2018, average yields of treatments ranged from 3147 to $3362 \mathrm{~kg} \mathrm{ha}^{-1}$. In 2019, average yields of treatment ranged from 603 to $657 \mathrm{~kg} \mathrm{ha}^{-1}$. Yields in 2019 were much lower than 2018, primarily due to two consecutive hailstorms that occurred around 8/15/2019. The hailstorms caused significant canopy defoliation among treatments. The CC percentage at the same sampling date increased with irrigation amounts (Fig. 2). Reduction of $\mathrm{CC}$ on 8/5 compared with the previous date was due to the picture taken under a different lighting condition (much brighter). This was the only time we encountered the issue, so no adjustment was made to the software. CC percentage after hailstorm damage was reduced on average by $43 \%$ at $0 \%$ treatment, $47 \%$ at $33 \%$ treatment, $51 \%$ at $66 \%$ treatment, and 54\% at $100 \%$ treatment (Fig. 2). Crop ET was not computed after the hailstorms. Heavier rainfall was received in 
Table 1 Irrigation rates, rainfall, yields, and cumulative $\mathrm{ET}_{\mathrm{C}}$ estimated by different methods in 2018 and 2019 growing season

\begin{tabular}{|c|c|c|c|c|c|c|c|c|c|c|c|}
\hline \multirow{4}{*}{$\begin{array}{l}\text { Trt } \\
\%\end{array}$} & \multirow{2}{*}{\multicolumn{2}{|c|}{$\mathrm{I}^{3}$}} & \multirow{2}{*}{\multicolumn{2}{|c|}{ Yield }} & \multicolumn{7}{|c|}{ Cumulative $\mathrm{ET}_{\mathrm{C}}{ }^{2}$} \\
\hline & & & & & \multicolumn{2}{|c|}{$\overline{\mathrm{PM}^{4}}$} & \multicolumn{2}{|l|}{$\mathrm{PT}^{5}$} & \multicolumn{2}{|c|}{ FAO56 $^{6}$} & \multirow{3}{*}{$\begin{array}{l}\mathrm{NP}^{7} \\
19\end{array}$} \\
\hline & 18 & 19 & 18 & $19^{1}$ & 18 & 19 & 18 & 19 & 18 & 19 & \\
\hline & \multicolumn{2}{|l|}{$\mathrm{mm}$} & \multicolumn{2}{|l|}{$\mathrm{kg} \mathrm{ha}^{-1}$} & \multicolumn{6}{|l|}{$\mathrm{mm}$} & \\
\hline 0 & 0 & 0 & $3147 \pm 223$ & $603 \pm 179$ & 117 & 74 & 114 & 77 & - & - & $79 \pm 3$ \\
\hline 33 & 37 & 40 & $3362 \pm 207$ & $657 \pm 146$ & 123 & 88 & 134 & 89 & - & - & $98 \pm 10$ \\
\hline 66 & 74 & 80 & $3307 \pm 284$ & $664 \pm 232$ & 128 & 115 & 212 & 115 & - & - & $128 \pm 3$ \\
\hline 100 & $\begin{array}{l}112 \\
\mathrm{~mm}\end{array}$ & 120 & $3209 \pm 151$ & $657 \pm 227$ & 103 & 141 & 166 & 137 & 152 & 131 & $150 \pm 16$ \\
\hline $\mathrm{P}^{3}$ & 74 & 24 & & & & & & & & & \\
\hline
\end{tabular}

${ }^{1}$ Yield in 2019 was significantly impacted by hailstorms. Approximate yield reduction was over $2000 \mathrm{~kg} \mathrm{ha}^{-1}$

${ }^{2}$ Cumulative $\mathrm{ET}_{\mathrm{C}}$ here are not seasonal $\mathrm{ET}_{\mathrm{C}}$ values. It refers to $\mathrm{ET}_{\mathrm{C}}$ values estimated by that method during IRT measurement period. In 2018, measurement period was from $7 / 7$ to $8 / 25$. In 2019 , measurement period was from $7 / 18$ to $8 / 14$

${ }^{3}$ Both Irrigation $(I)$ and Precipitation $(P)$ are cumulative values from $7 / 7$ to $8 / 25$ in 2018 , and $7 / 18$ to $8 / 14$ in 2019 to match periods when cumulative $\mathrm{ET}_{\mathrm{C}}$ were calculated

${ }^{4} \mathrm{ET}_{\mathrm{C}}$ estimate using TSEB Penman-Monteith model

${ }^{5} \mathrm{ET}_{\mathrm{C}}$ estimate using TSEB Priestley-Taylor model

${ }^{6} \mathrm{ET}_{\mathrm{C}}$ estimate using standard single-crop coefficient FAO56 procedure

${ }^{7} \mathrm{ET}_{\mathrm{C}}$ estimate using soil water balance method using soil moisture data from neutron probe

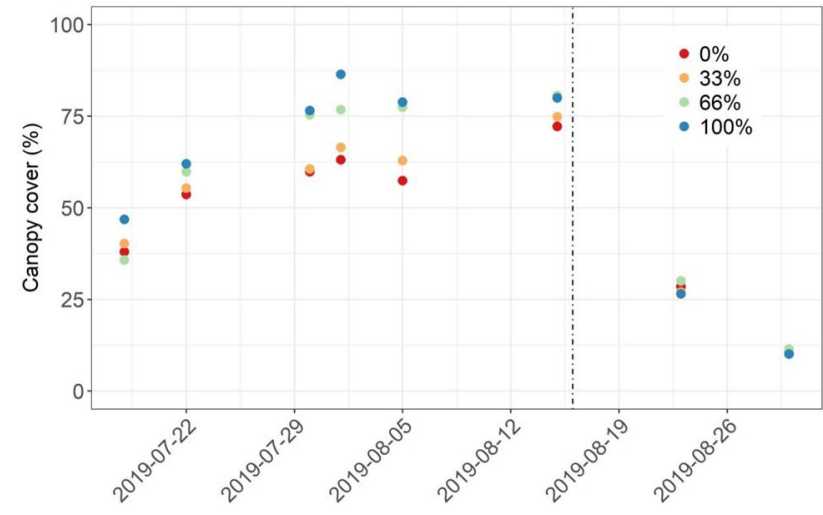

Fig. 2 Canopy cover for four irrigation treatments between 7/18/2019 and $8 / 31 / 2019$. Dashed line indicates when crop was damaged by hailstorms on $8 / 15 / 2019$

2019 growing season, as shown in Fig. 3 and Table 1. In both years, yields were not significantly different among treatments ( $p=0.69$ and 0.68 for 2018 and 2019, respectively).

\section{Performance of Crop Canopy Image Analyzer (CCIA)}

\section{Canopy cover $\left(\mathrm{f}_{\mathrm{s}}\right)$ detection}

Depending on actual computer configuration, it takes $2-3 \mathrm{~s}$ to process one image using CCIA. An example on sampling date $7 / 22 / 19$ of processed surface area of dry edible bean canopy by Md method with different irrigation treatments

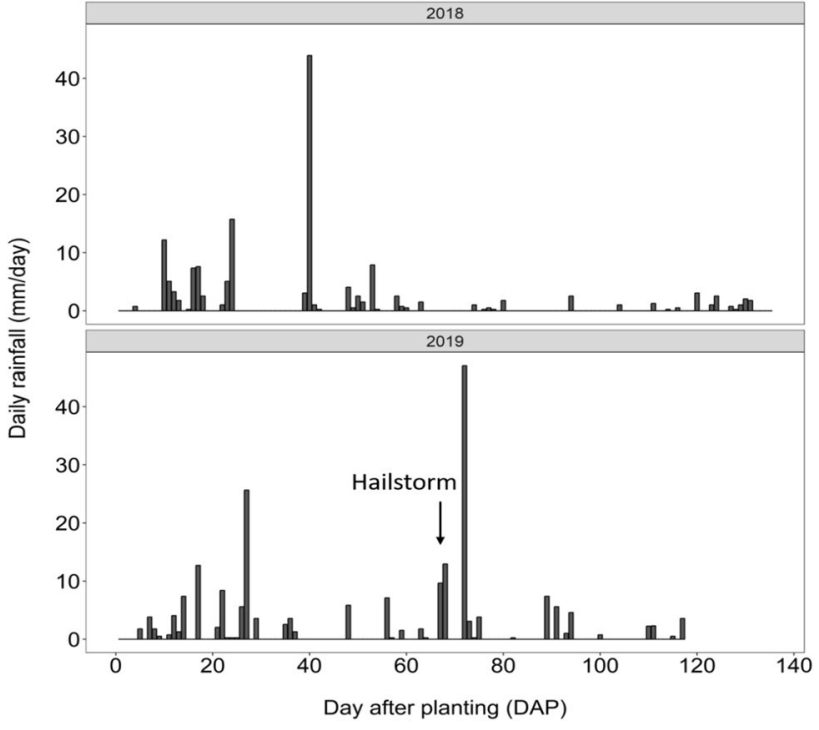

Fig. 3 Rainfall during 2018 and 2019 growing season

is shown in Fig. 4. It can be seen that dark soil pixels, crop residual pixels, and shadows pixels were properly filtered. The classifiers for 6 reference groups performed well without any adjustments of contrast, brightness, or color. The average CC percentage were 53,55, 60, and $62 \%$ at irrigation treatment $0,33,66$, and $100 \%$, respectively (Fig. 4). This CC detection method provided accurate estimation of $\mathrm{CC}$ percentage at different treatments. To validate $f_{S}$, the 


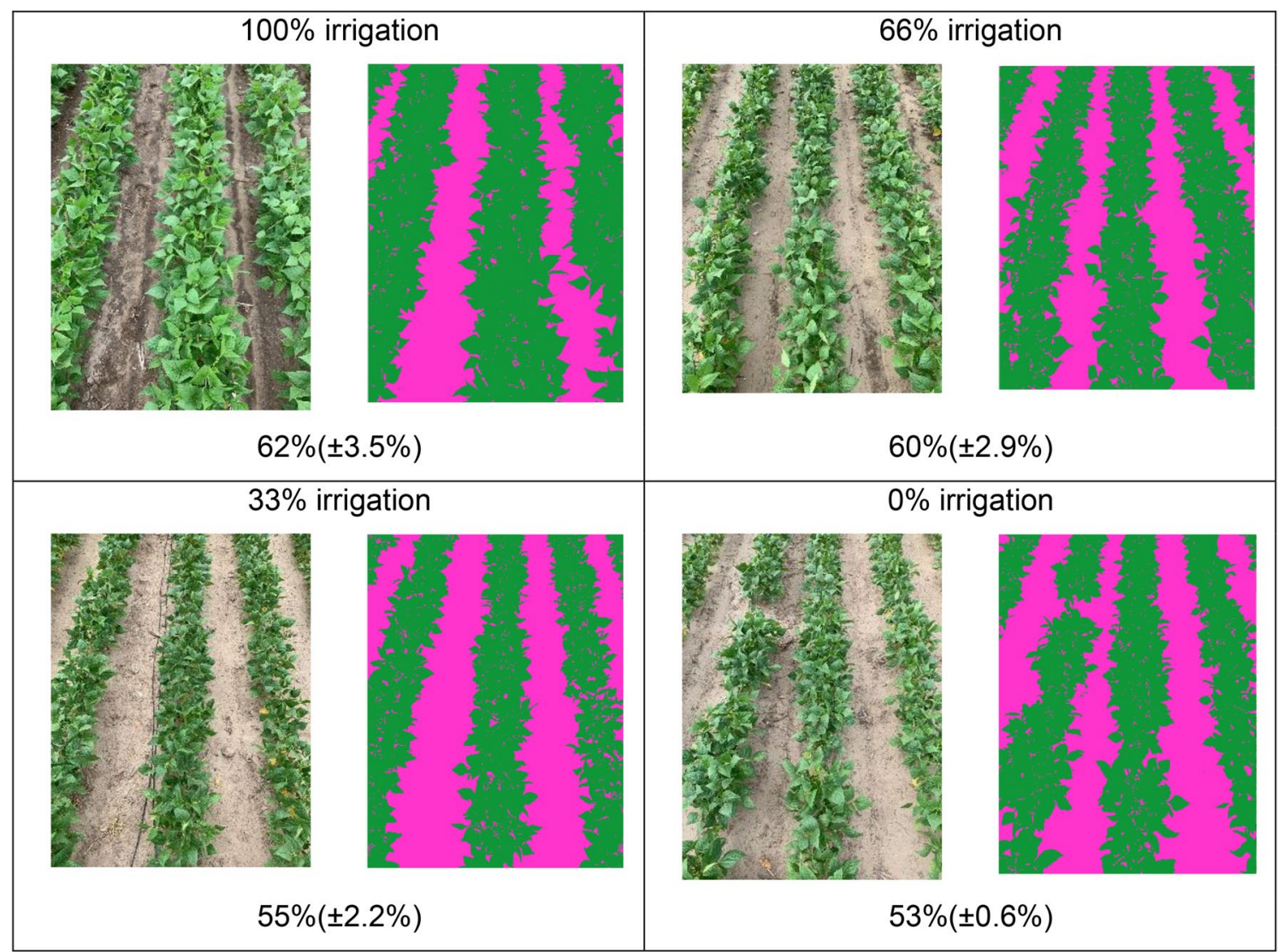

Fig. 4 An example of original and processed canopy cover image of four irrigation treatments of dry bean on 07/22/19 using Crop Canopy Image Analyzer (CCIA)

pairs of canopy images and corresponding LAI taken on July 18th, July 30th, and August 5th, 2019 at three replicates of each irrigation treatment were selected $(n=26)$. The average error between $f_{S}$ and $f_{\text {LAI }}$ was $3.9 \%$, and RMSE and $R^{2}$ were $4.39 \%$ and 0.96 , respectively (Fig. 5). Overall, the simulated $f_{S}$ provided reasonable estimation compared to $\mathrm{f}_{\mathrm{LAI}}$ and was used in the calculation of TSEB models.

\section{Leaf shape factor $\left(L_{s}\right)$ detection}

Dry edible bean leaf image was processed for A and P in the software. An example is shown in Fig. 6, where an identified leaf was transformed to green color and the background was transformed to pink color in the output figure (Fig. 6b). During 2019 growing season, dry edible bean leaf images taken on July 18th, July 30th, and August 5 th at each irrigation treatment with three replicates were selected $(n=100)$ for creating regression between $L_{S}$ and $L_{\text {meas }}$ and to obtain $\lambda$. With Md and Canny edge detection methods, the software-estimated $\mathrm{L}_{\mathrm{S}}$ had very well relationship with $L_{\text {meas }}$ by having $R^{2}$ of 0.99 and slope of 1 (Fig. 7). Therefore, the coefficient $\lambda$ was 1 in this study. To our best knowledge, there have been no studies that use

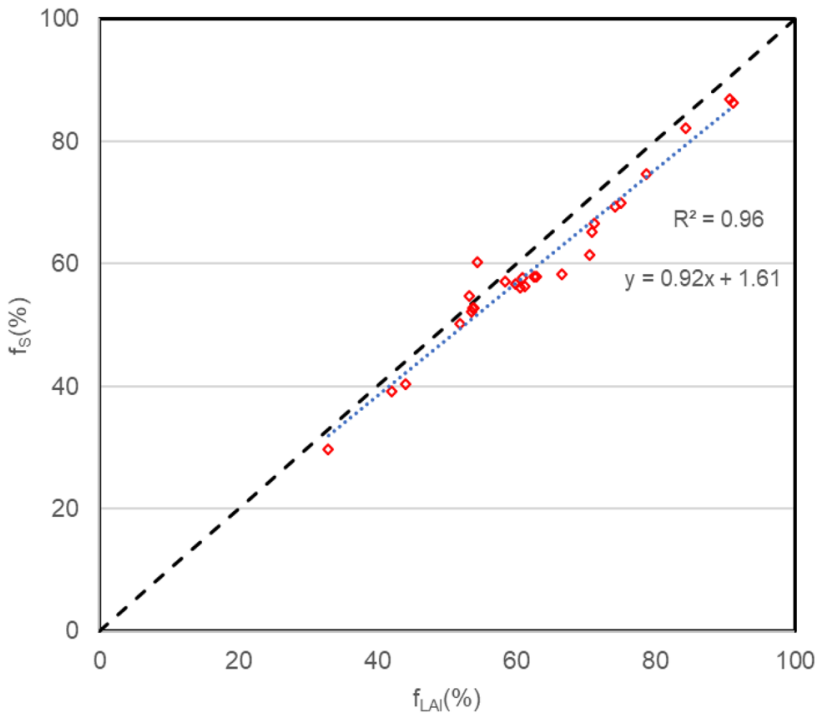

Fig. 5 Comparison between canopy cover percentage estimated from LI-COR LAI2000 $\left(f_{\text {LAI }}\right)$ and estimated using Crop Canopy Image Analyzer $\left(f_{S}\right)$. Note: dotted line is $1: 1$ line $(\mathrm{RMSE}=4.39 \%, p<0.01$, $n=26$ ) 

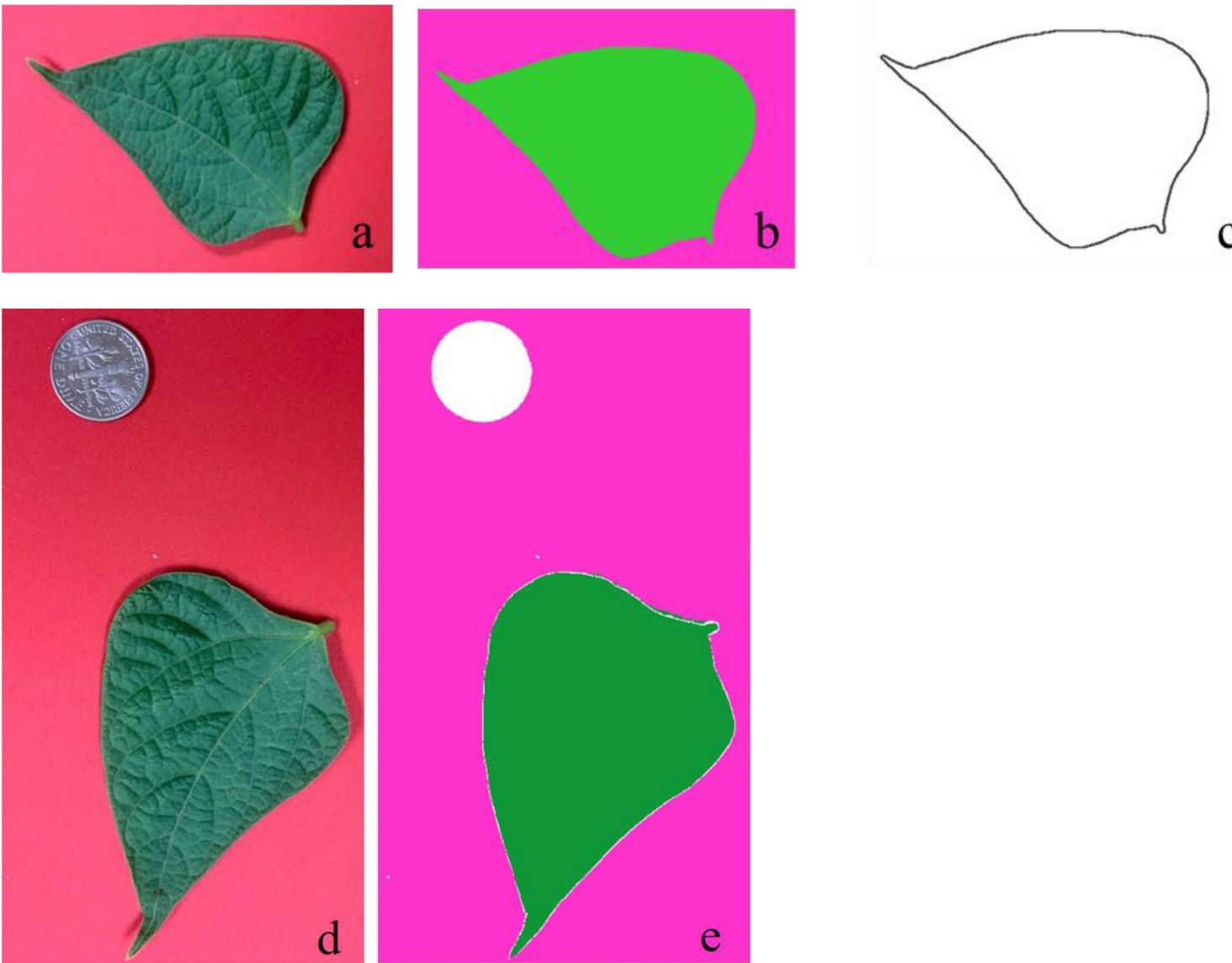

Fig. 6 a Original leaf image, $\mathbf{b}$ green area of identified leaf using Mahalanobis distance, $\mathbf{c}$ perimeter of identified leaf using canny edge detection algorithm $\left(t_{1}=7, t_{2}=20\right)$, $\mathbf{d}$ original leaf and coin, and e processed leaf and coin image

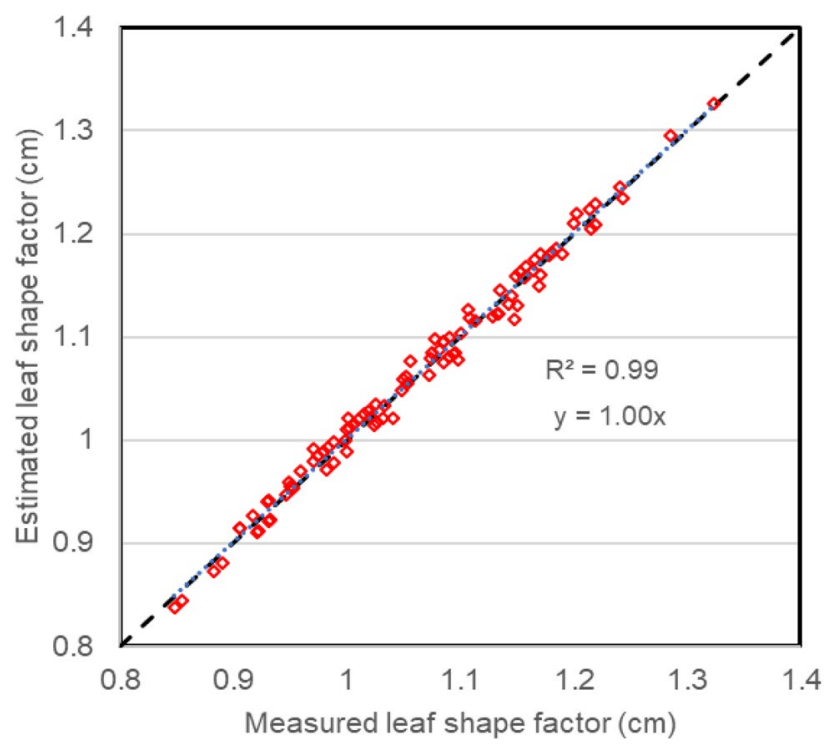

Fig. 7 Regression between estimated leaf shape factor $\left(L_{s}\right)$ versus measured leaf shape factor $\left(L_{\text {meas }}\right)$. Note: dotted line is $1: 1$ line $(n=100)$ leaf area and leaf perimeter pixel number to estimate leaf shape factor that is used in the TSEB models. Previous studies measuring leaf area and shape have used visual estimates (Stotz et al. 2000), desktop scanners (O'Neal et al. 2002), or portable leaf area meters (O'Neal et al. 2002; Malone et al. 2002). Measurement using scanners is time-consuming, expensive, and labor-intensive. The method proposed in this study is faster, easier, and nondestructive by only requiring a regular camera taking RGB images, and minimal computer processing effort.

Two-way ANOVA (SAS 2014) was used to determine if there is significant difference between leaf area from different dates and irrigation treatments. The results of the twoway ANOVA with replication showed that $L_{S}$ had no interaction between dates and treatments $(p=0.446)$ (Fig. 8). The effect of date $(F=6.42, p=0.0027)$ and irrigation treatments $(F=12.03, p<0.001)$ are significant. The $\mathrm{L}_{\mathrm{S}}$ on $7 / 18 / 2019$ is significantly lower than the $\mathrm{L}_{\mathrm{S}}$ on $7 / 30 / 2019$ and 8/9/2019. The $L_{S}$ for $0 \%$ irrigation treatment is significantly lower than the 33,66 , and $100 \%$ treatments. Therefore, $\mathrm{L}_{\mathrm{S}}$ for different dates and treatments should be varied instead of assuming 


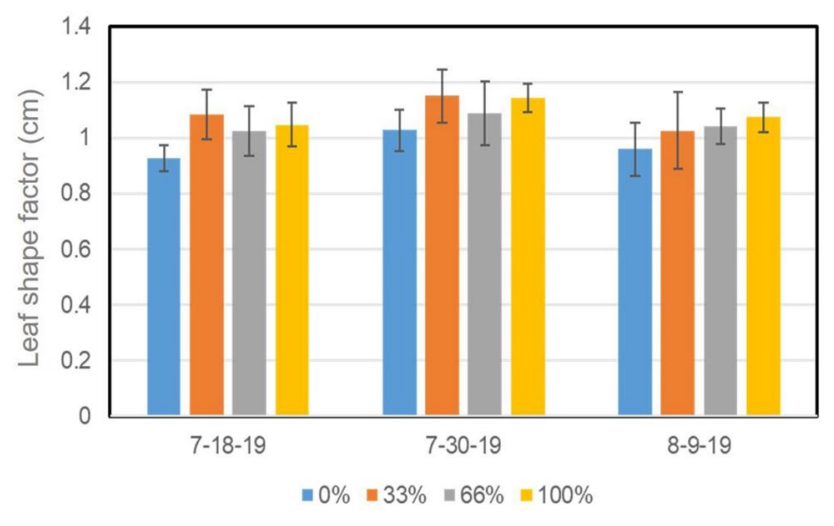

Fig. 8 Mean of leaf shape factor on three sampling dates of the four irrigation treatments. Values are mean \pm standard deviation $(n=25$ for each treatment on each sampling date)

a constant value for whole experimental design, which can provide a better assessment of $\mathrm{ET}_{\mathrm{C}}$.

\section{Crop evapotranspiration estimation using TSEB models}

Both TSEB-PM and TSEB-PT models were calculated hourly. For convenience of representation and comparison, hourly modeled $\mathrm{ET}_{\mathrm{C}}$ values within a day $(24 \mathrm{~h}$, from 0:00 to 23:00) were summed to provide daily ET values and are referred as $\mathrm{ET}_{\mathrm{TSEB}-\mathrm{PT}}$ and $\mathrm{ET}_{\mathrm{TSEB}-\mathrm{PM}}$ hereafter. The average ET $_{\text {TSEB-PM }}$ of the $0,33,66$, and $100 \%$ were $3.2 \mathrm{~mm} \mathrm{day}^{-1}$, $3.4 \mathrm{~mm} \mathrm{day}^{-1}, 4.9 \mathrm{~mm} \mathrm{day}^{-1}$, and $4.8 \mathrm{~mm} \mathrm{day}^{-1}$, respectively. The average $\mathrm{ET}_{\text {TSEB-PT }}$ of the $0,33,66$, and $100 \%$ were $3.0 \mathrm{~mm} \mathrm{day}^{-1}, 3.2 \mathrm{~mm} \mathrm{day}^{-1}, 5.2 \mathrm{~mm} \mathrm{day}^{-1}$, and $4.9 \mathrm{~mm} \mathrm{day}^{-1}$, respectively. Crop evapotranspiration calculated from FAO-56 and soil water balance using neutron probe are, respectively, referred as $\mathrm{ET}_{\mathrm{FAO56}}$ (both 2018 and 2019 growing season) and $\mathrm{ET}_{\mathrm{NP}}$ (2019 growing season only) and were used as reference in this study. Although $\mathrm{ET}_{\mathrm{C}}$ from FAO56 are not actual measurements but rather modeled values, FAO56 remains popular in comparing with other ET calculation procedures like TSEB model (Diarra et al. 2017) and soil water content-based ET calculation (Sau et al. 2004). Many other TSEB-related research use Eddy Covariance/energy balance systems (Timmermans et al. 2007; Hoffman et al. 2016; Nieto et al. 2019) or lysimeter (Colaizzi et al. 2012) or sap flow gauges (Colaizzi et al. 2014) to validate/evaluate components of TSEB models. Eddy Covariance tower was not available during time of this study nor suitable due to treatment plots were too small $(9 \mathrm{~m} \times 15 \mathrm{~m})$ compared to footprint of Eddy Covariance tower.

During 2018 growing season, modeled ET TSEB-PM $_{\text {and }}$ $\mathrm{ET}_{\mathrm{TSEB}-\mathrm{PT}}$ for the $100 \%$ irrigation treatment were compared with $\mathrm{ET}_{\mathrm{FAO56}}$ (Fig. 9). The $R^{2}$ of $\mathrm{ET}_{\mathrm{TSEB}-\mathrm{PM}}$ for rep 1 and rep 2 of $100 \%$ irrigation treatment were 0.93 and 0.75 , whereas the $R^{2}$ of $\mathrm{ET}_{\mathrm{TSEB}-\mathrm{PT}}$ versus $\mathrm{ET}_{\mathrm{FAO56}}$ were 0.72 and 0.82, respectively (Fig. 9). The RMSE of ET TSEB-PM with $\mathrm{ET}_{\mathrm{FAO} 56}$ for rep 1 and rep 2 of $100 \%$ irrigation treatment were 1.04 and $1.63 \mathrm{~mm}$ day $^{-1}$, whereas the RMSE of $\mathrm{ET}_{\mathrm{TSEB}-\mathrm{PT}}$ with $\mathrm{ET}_{\mathrm{FAO}_{6} 6}$ were 1.29 and $0.95 \mathrm{~mm} \mathrm{day}^{-1}$, respectively (Fig. 9). The analysis showed that TSEB-PM and TSEB-PT model demonstrated reasonable prediction of daily $\mathrm{ET}_{\mathrm{C}}$ in 2018 growing season.

During 2019 growing season, similar to 2018, $\mathrm{ET}_{\mathrm{TSEB}-\mathrm{PM}}$ and $\mathrm{ET}_{\mathrm{TSEB}-\mathrm{PT}}$ of the $100 \%$ irrigation treatment

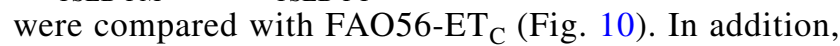
$\mathrm{ET}_{\mathrm{TSEB}-\mathrm{PM}}$ and $\mathrm{ET}_{\mathrm{TSEB}-\mathrm{PT}}$ of all treatments were compared with $\mathrm{ET}_{\mathrm{NP}}$ between July 18th and August 14th before the hailstorm happened. The daily $\mathrm{ET}_{\mathrm{C}}$ among four irrigation treatments showed significant differences $(p=0.013)$ calculated by Tukey's honest significance test during the 2019 growing season. The average $\mathrm{ET}_{\mathrm{TSEB}-\mathrm{PM}}$ of the 0,33 , 66 , and $100 \%$ were $2.4 \mathrm{~mm} \mathrm{day}^{-1}, 3.3 \mathrm{~mm}_{\text {day }}{ }^{-1}, 4.2 \mathrm{~mm}$ day $^{-1}$, and $4.9 \mathrm{~mm} \mathrm{day}^{-1}$, respectively. The average $\mathrm{ET}_{\mathrm{TSEB}-\mathrm{PT}}$ of the $0 \%, 33 \%, 66 \%$, and $100 \%$ were $2.5 \mathrm{~mm}$ day $^{-1}, 3.4 \mathrm{~mm} \mathrm{day}^{-1}, 4.3 \mathrm{~mm} \mathrm{day}^{-1}$, and $5.1 \mathrm{~mm}$ day $^{-1}$, respectively. The $R^{2}$ of $\mathrm{ET}_{\mathrm{FAO} 56}$ with $\mathrm{ET}_{\mathrm{TSEB}-\mathrm{PM}}$ at $100 \%$ irrigation treatment ranged from 0.73 to 0.88 , whereas the $R^{2}$ with $\mathrm{ET}_{\mathrm{TSEB}-\mathrm{PT}}$ ranged from only 0.60 to 0.75 during the 2019 growing season. The RMSE of ET FAO56 $_{\text {with }}$ ET $_{\text {TSEB-PM }}$ model ranged between 0.86 and $1.14 \mathrm{~mm}$ day $^{-1}$, whereas with ET $_{\text {TSEB-PT }}$, the RMSE ranged from 0.96 and $1.34 \mathrm{~mm} \mathrm{day}^{-1}$. Across 2 years, the reported RMSE are similar to results reported in Colaizzi et al. (2014), where TSEB modeled ET had RMSE ranging from 0.9 to $3.2 \mathrm{~mm}$ day $^{-1}$ at a well-irrigated cotton field located under a semiarid climate.

For $\mathrm{ET}_{\mathrm{NP}}$, since neutron probe readings were taken on weekly basis, $\mathrm{ET}_{\mathrm{NP}}$ was also reported weekly $\left(\mathrm{mm}\right.$ week $\left.^{-1}\right)$. The RMSE of $\mathrm{ET}_{\mathrm{NP}}$ with $\mathrm{ET}_{\mathrm{TSEB}-\mathrm{PM}}$ model ranged between 2.0 and $9.1 \mathrm{~mm}^{\text {week }}{ }^{-1}$, whereas with $\mathrm{ET}_{\mathrm{TSEB}-\mathrm{PT}}$, the RMSE ranged from 3.3 to $9.7 \mathrm{~mm} \mathrm{week}^{-1}$. Details of RMSE values are shown in Table 2. Neutron probe measured ET of dry edible bean correlated with $\mathrm{ET}_{\mathrm{TSEB}-\mathrm{PT}}$ and $\mathrm{ET}_{\mathrm{TSEB}-\mathrm{PM}}$ well by having a slope of 0.99 and 1.03 and $R^{2}$ of 0.71 and 0.82 , respectively (Fig. 11). The RMSE of $\mathrm{ET}_{\mathrm{TSEB}-\mathrm{PT}}$ with $\mathrm{ET}_{\mathrm{NP}}$ across four irrigation treatments is $7.62 \mathrm{~mm}^{\text {week }}{ }^{-1}$, whereas the RMSE of $\mathrm{ET}_{\mathrm{TSEB}-\mathrm{PM}}$ with $\mathrm{ET}_{\mathrm{NP}}$ across four irrigation treatments is $6.10 \mathrm{~mm} \mathrm{week}^{-1}$. French et al. (2015) reported a difference of $\sim 2 \mathrm{~mm} \mathrm{day}^{-1}$ between crop ET from NP and ET calculated from TSEB or METRIC, acknowledging that the study compared ET at discrete days, whereas this study compared ET at a continuous timeframe. We also noticed that TSEB-PM consistently outperformed TSEB-PT in terms of RMSE for all four irrigation treatments (Table 2 and Fig. 11), which agrees with findings in Colaizzi et al. (2014). 


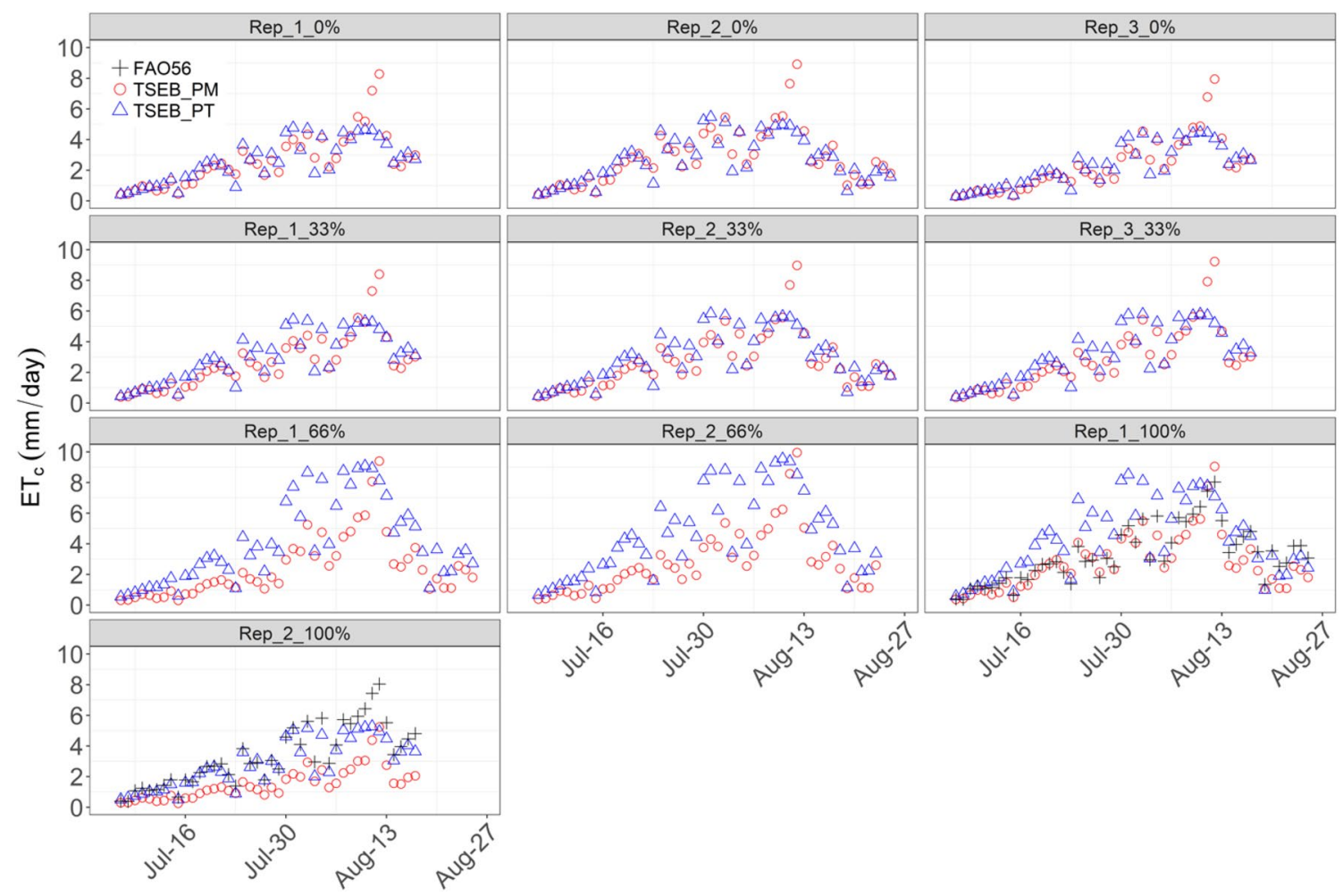

Fig. 9 Daily ET $_{\mathrm{C}}$ of FAO56 (100\% only), TSEB-PM, and TSEB-PT among 4 different irrigation treatments in 2018 growing season

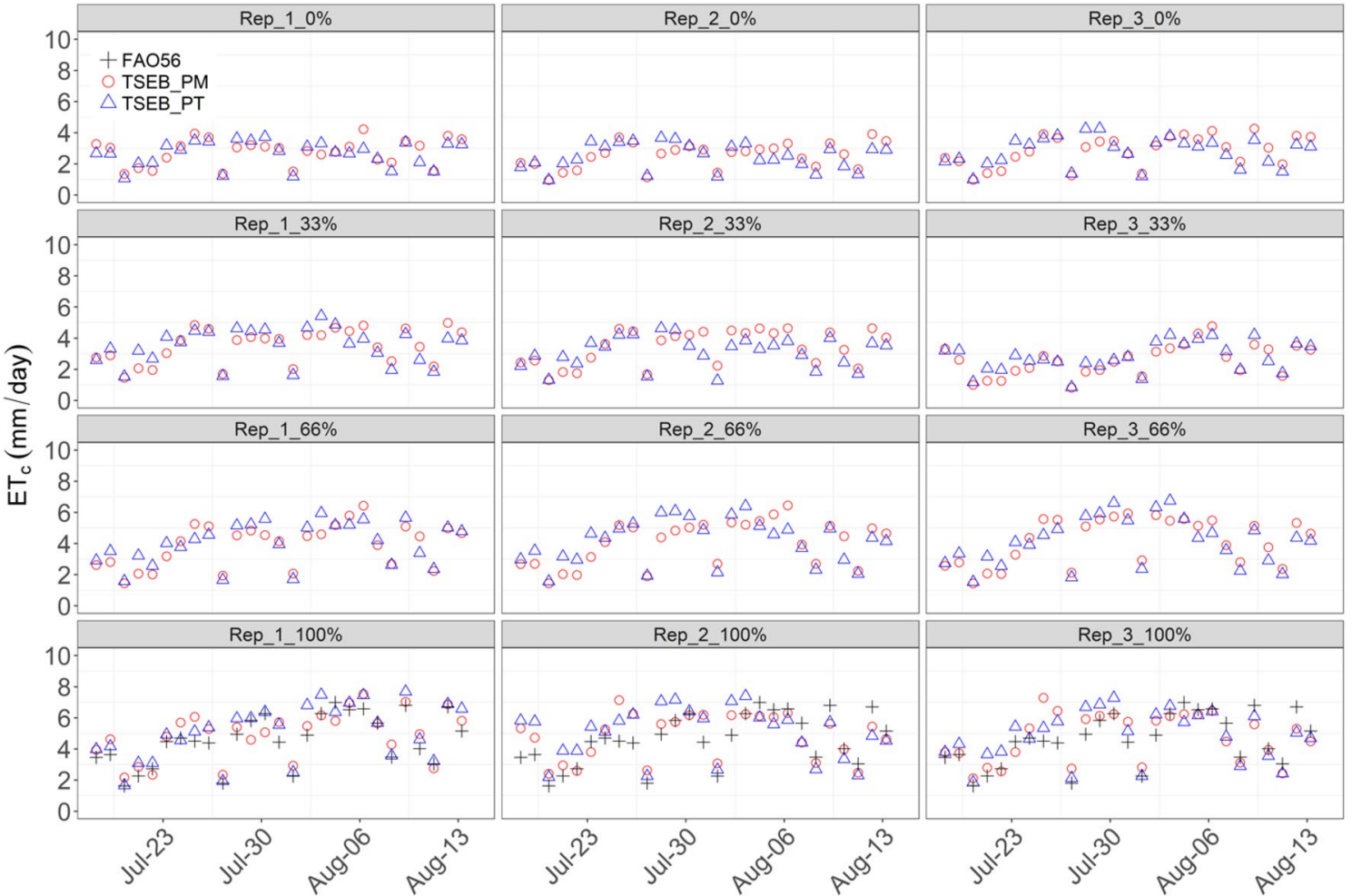

Fig. 10 Daily ET $_{\mathrm{C}}$ of FAO56 (100\% irrigation treatment only), TSEB-PM, and TSEB-PT among 4 different irrigation treatments in 2019 growing season 
Table 2 RMSE of TSEBPM and TSEB-PT models vs. neutron probe weekly evapotranspiration $\left(\mathrm{mm} \mathrm{week}^{-1}\right)$ in 4 irrigation treatments data set during 2019 study

\begin{tabular}{|c|c|c|c|c|c|c|c|c|c|c|c|c|}
\hline \multirow{2}{*}{$\begin{array}{l}\text { Trt } \\
\text { Rep }\end{array}$} & \multicolumn{3}{|l|}{$0 \%$} & \multicolumn{3}{|l|}{$33 \%$} & \multicolumn{3}{|l|}{$66 \%$} & \multicolumn{3}{|c|}{$100 \%$} \\
\hline & 1 & 2 & 3 & 1 & 2 & 3 & 1 & 2 & 3 & 1 & 2 & 3 \\
\hline PT & 3.30 & 6.86 & 5.33 & 8.89 & 7.87 & 5.84 & 7.37 & 9.65 & 8.64 & 9.40 & 5.59 & 8.89 \\
\hline PM & 2.03 & 4.32 & 2.79 & 6.60 & 5.33 & 4.32 & 5.84 & 6.60 & 7.37 & 9.14 & 4.32 & 8.38 \\
\hline
\end{tabular}

${ }^{1}$ In some cases, neutron probe readings were not taken at exact weekly basis

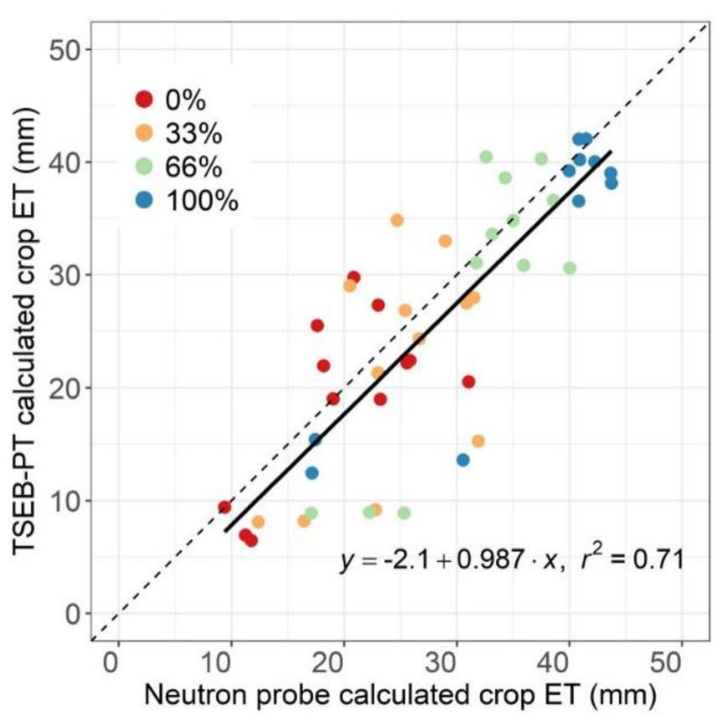

Fig. 11 Comparison of the TSEB-PT calculated $E T_{C}$ (left) and TSEB-PM calculated $E T_{C}$ (right) with neutron probe calculated ET on an approximately weekly basis. Note: dotted line is 1:1 line. For

\section{Conclusions}

This study described a methodology to estimate dry edible bean $\mathrm{ET}_{\mathrm{C}}$ that involves canopy temperature measurement using IRT, digital canopy analysis using RGB images, and computation with TSEB models in semi-arid western Nebraska. Key findings are:

1. The Visual Basic software CCIA using Mahalanobis distance and Canny edge detection provide a quick, user-friendly, and accurate way to estimate canopy parameters that are required in the TSEB models. We noticed that leaf shape factor can be significantly different among different dates and irrigation treatments. Therefore, it is suggested to measure these values rather than using constant values when computing TSEB models.

2. Both TSEB-PT- and TSEB-PM-based models provided good estimates of $\mathrm{ET}_{\mathrm{C}}$ compared with FAO56 and the soil water balance method using neutron probe readings. Furthermore, $\mathrm{ET}_{\mathrm{C}}$ from TSEB models agreed well with

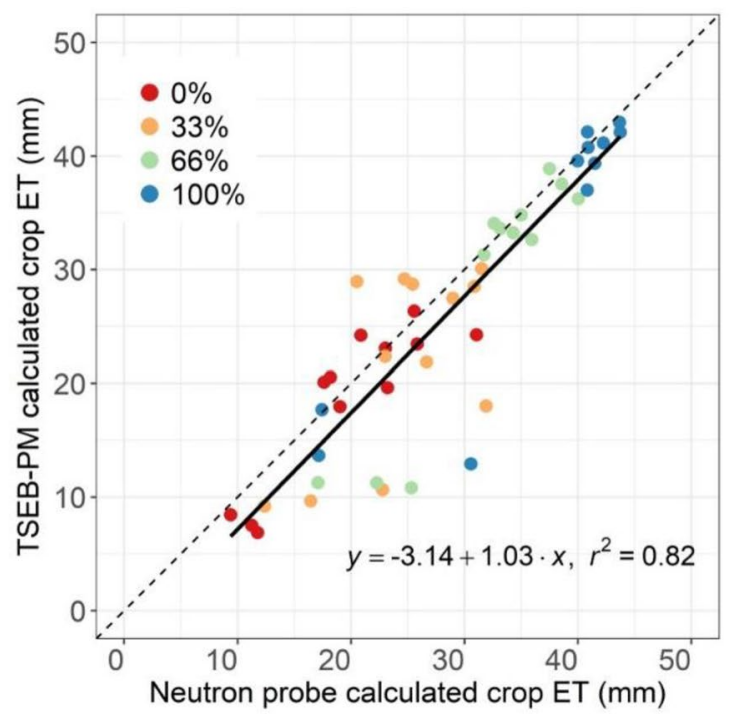

$\mathrm{ET}_{\mathrm{TSEB}-\mathrm{PT}}$ with $\mathrm{ET}_{\mathrm{NP}}, \mathrm{RMSE}$ is $7.62 \mathrm{~mm} \mathrm{week}^{-1}\left(\sim 1.09 \mathrm{~mm} \mathrm{day}^{-1}\right)$, $p<0.001$. For $\mathrm{ET}_{\mathrm{TSEB}-\mathrm{PM}}$ with $\mathrm{ET}_{\mathrm{NP}}, \mathrm{RMSE}$ is $6.10 \mathrm{~mm} \mathrm{week}^{-1}$ $\left(\sim 0.87 \mathrm{~mm}^{-}\right.$day $\left.^{-}\right), p<0.001$

$\mathrm{ET}_{\mathrm{C}}$ from soil water balance method under four irrigation treatments $(0,33,66$, and $100 \%)$ at the plot scale.

The results indicated that IRT and TSEB models provided a reasonable estimation of $\mathrm{ET}_{\mathrm{C}}$ for dry edible beans in western Nebraska. In addition, using digital images, it provides an easier and more approachable way to manage irrigation using IRT and TSEB models. However, the current work is limited in the way that (1) we were not able to evaluate flux components of TSEB models, so the accuracy of simulated $\mathrm{E}$ and $\mathrm{T}$ was unknown; (2) the comparison of ET from TSEB models versus ET from neutron probe readings was coarse in terms of temporal resolution (weekly). Finer temporal resolution ET values from dependable means are desired to further examine the accuracy of this approach in the future.

Acknowledgements We greatly appreciate the financial support from Nebraska Dry Bean Commission on this project. This research project is also supported by the U.S. Department of Agriculture National Institute of Food and Agriculture (Hatch project NEB-21-177, accession number 1015698). 


\section{Compliance with ethical standards}

Conflict of interest On behalf of all authors, the corresponding author states that there is no conflict of interest.

\section{References}

Allen RG, Pereira LS, Raes D, Smith M (1998) Crop evapotranspiration-Guidelines for computing crop water requirements-FAO Irrigation and drainage paper 56. Irrigation and Drainage, 1-15

Allen RG, Irmak A, Trezza R, Hendrickx JM, Bastiaanssen W, Kjaersgaard J (2011) Satellite-based ET estimation in agriculture using SEBAL and METRIC. Hydrol Process 25(26):4011-4027

Benli B, Bruggeman A, Oweis T, Üstün H (2010) Performance of Penman-Monteith FAO56 in a semiarid highland environment. J Irrigation Drainage Eng 136(11):757-765

Canny J (1986) A computational approach to edge detection. IEEE Trans Pattern Anal Mach Intell 8(6):679-698

Colaizzi PD, O'Shaughnessy SA, Gowda PH, Evett SR, Howrll TA, Kustas WP (2010) Radiometer footprint model to estimate sunlit and shaded components for tow crops. Agron J 102:942-955

Colaizzi PD, Kustas WP, Anderson MC, Agam N, Tolk JA, Evett SR, Howell TA, Gowda PH, O'Shaughnessy SA (2012) Two-source energy balance model estimates of evapotranspiration using component and composite surface temperatures. Adv Water Resour 50:134-151

Colaizzi PD, Agam N, Tolk JA, Evett SR, Howell TA, Gowda PH, O'Shaughnessy SA, Kustas WP, Anderson MC (2014) Twosource energy balance model to calculate E, T, and ET: comparison of Priestley-Taylor and Penman-Monteith formulations and two time scaling methods. Trans ASABE 57(2):479-498

Devroye L, Gyorfi L, Lugosi G (1996) A probabilistic theory of pattern recognition, 1st edn. Springer, New York

Dhungel R, Allen RG, Trezza R, Robison CW (2016) Evapotranspiration between satellite overpasses: methodology and case study in agricultural dominant semi-arid areas. Meteorol Appl 23(4):714-730

Dhungel R, Aiken R, Colaizzi PD, Lin X, O'Brien D, Baumhardt RL, Brauer DK, Marek GW (2018) Evaluation of uncalibrated energy balance model (BAITSS) for estimating evapotranspiration in a semiarid, advective climate. Hydrol Process 33(15):2110-2130

Di Virgilio N, Monti A, Venturi G (2007) Spatial variability of switchgrass (Panicum virgatum L.) yield as related to soil parameters in a small field. Field Crops Res 101(2):232-239

Diarra A, Jarlan L, Er-Raki S, Le Page M, Aouade G, Tavernier A, Boulet G, Ezzahar J, Merlin O, Khabba S (2017) Performance of the two-source energy budget (TSEB) model for the monitoring of evapotranspiration over irrigated annual crops in North Africa. Agric Water Manag 193:71-88

Evett SR, Tolk JA, Howell TA (2006) Soil profile water content determination. Vadose Zone J 5(3):894-907

Evett SR, Schwartz RC, Casanova JJ, Heng LK (2012) Soil water sensing for water balance, ET and WUE. Agric Water Manag 104:1-9

French AN, Hunsaker DJ, Thorp KR (2015) Remote sensing of evapotranspiration over cotton using the TSEB and METRIC energy balance models. Remote Sens Environ 158:281-294

Hoffman H, Nieto H, Jensen R, Guzinski R, Zarco-Tejada P, Friborg T (2016) Estimating evaporation with thermal UAV data and twosource energy balance models. Hydrol Earth Syst Sci 20:697-713

Kamble B, Kilic A, Hubbard K (2013) Estimating crop coefficients using remote sensing-based vegetation index. Remote Sens 5(4):1588-1602
Kravchenko AN, Bullock DG (2000) Correlation of corn and soybean grain yield with topography and soil properties. Agron J 92(1):75-83

Kustas WP, Norman JM (1999) Evaluation of soil and vegetation heat flux predictions using a simple two-source model with radiometric temperatures for partial canopy cover. Agric Forest Meteorol 94:13-29

Kwon H, Choi M (2011) Error assessment of climate variables for FAO-56 reference evapotranspiration. Meteorol Atmos Phys 112(1-2):81-90

Li F, Kustas WP, Prueger JH, Neale CMU, Jackson TJ (2005) Utility of remote sensing based two-source energy balance model under low and high vegetation cover conditions. J Hydromet 6:878-891

Liang W-Z, Kirk KR, Greene JK (2018) Estimation of soybean leaf area, edge, and defoliation using image analysis. Comput Electron Agric 150:41-51

Malone S, Herbert DM, Holshouser DL (2002) Evaluation of the LAI2000 plant canopy analyzer to estimate leaf area in manually defoliated soybean. J Agronomy 94:1012-1019

Neale CMU, Bausch WC, Heermann DF (1990) Development of reflectance-based crop coefficients for corn. Trans ASAE 32(6): 1891-1900

Nieto H, Kustas WP, Torres-Rúa A, Alfieri JG, Gao F, Anderson MC, White WA, Song L, del Mar AM, Prueger JH, McKee M (2019) Evaluation of TSEB turbulent fluxes using different methods for the retrieval of soil and canopy component temperatures from UAV thermal and multispectral imagery. Irrig Sci 37(3):389-406

Norman JM, Kustas WP, Humes KS (1995) A two-source approach for estimating soil and vegetation energy fluxes from observations of directional radiometric surface temperature. Agric Forestry Meteorol 77:263-293

North Platte Natural Resources District (2019) Rules \& Regulations For the Enforcement of the Nebraska Ground Water Management and Protection Act and the Nebraska Chemigation Act

O’Neal ME, Landis DA, Issacs R (2002) An inexpensive, accurate method for measuring leaf area and defoliation through digital image analysis. J Econ Entomol 95(6):1190-1194

Papadavid G, Hadjimitsis DG, Toulios L, Michaelides S (2013) A modified SEBAL modeling approach for estimating crop evapotranspiration in semi-arid conditions. Water Resour Manage 27(9):3493-3506

Pereira LS, Allen RG, Smith M, Raes D (2015) Crop evapotranspiration estimation with FAO56: Past and future. Agric Water Manag 147:4-20

SAS software, Version 9.4 for Windows was used for this analysis. Copyright (C) (2014) SAS Institute Inc. SAS and all other SAS Institute Inc. product or service names are registered trademarks or trademarks of SAS Institute Inc., Cary

Sau F, Boote KJ, Bostick WM, Jones JW, Mínguez MI (2004) Testing and improving evapotranspiration and soil water balance of the DSSAT crop models. Agron J 96(5):1243-1257

Singh RK, Irmak A, Irmak S, Martin DL (2008) Application of SEBAL model for mapping evapotranspiration and estimating surface energy fluxes in south-central Nebraska. J Irrigation Drainage Eng 134(3):273-285

Singh J, Lo T, Rudnick DR, Dorr TJ, Burr CA, Werle R, Muñoz-Arriola F (2018) Performance assessment of factory and field calibrations for electromagnetic sensors in a loam soil. Agric Water Manag 196:87-98

Sobel I (1978) Neighborhood coding of binary images fast contour following and general array binary processing. Comput Graphics Image Proc 8:127-135

Stotz HU, Pittendrigh BR, Kroymann J, Weniger K, Fritsche J, Bauke A, Mitchell-Olds T (2000) Induced plant defense responses against chewing insects: ethylene signaling reduces resistances of 
Arabidopsis against Egyptian cotton worm but not diamondback moth. Plant Physiol 124:1007-1019

Timmermans WJ, Kustas WP, Anderson MC, French AN (2007) An intercomparison of the surface energy balance algorithm for land (SEBAL) and the two-source energy balance (TSEB) modeling schemes. Remote Sens Environ 108(4):369-384

University of Nebraska Extension (2020) Crop Water Use by Growth Stage-Dry Beans. https://cropwatch.unl.edu/et_resources. Accessed 1 December 2020

University of Nebraska Extension, University of Wyoming Extension (2019) Recovering from 2019 Canal Breach. https://extension. unl.edu/statewide/panhandle/canal-break/. Accessed 1 December 2020

USDA (2013) Farm and Ranch Irrigation Survey
Yang Y, Qiu J, Zhang R, Huang S, Chen S, Wang H, Luo J, Fan Y (2018) Intercomparison of three two-source energy balance models for partitioning evaporation and transpiration in semiarid climates. Remote Sens 10:1149

Yonts CD, Haghverdi A, Reichert DL, Irmak S (2018) Deficit irrigation and surface residue cover effects on dry bean yield, in-season soil water content and irrigation water use efficiency in western Nebraska high plains. Agric Water Manag 199:38-147

Publisher's Note Springer Nature remains neutral with regard to jurisdictional claims in published maps and institutional affiliations. 